Studia Slavica Savariensia 2018. 1-2. 92-99

DOI: $10.17668 /$ SSS.2018.1-2.92

\author{
Kalafatics Zsuzsanna ${ }^{1}$ \\ (Будапешт, Венгрия)
}

\title{
РОЛЬ СИМВОЛИСТСКОЙ ТРАДИЦИИ В СОЗДАНИИ ДИХОТОМИЧЕСКОГО МИРА РОМАНА В КРУГЕ ПЕРВОМ А. СОЛЖЕНИЦЫНА
}

\begin{abstract}
The paper is focused upon Solzhenitsyn's novel The First Circle. Though the author did correlate modernist experimentations with the language of the novel genre and style with destruction brought about by 1917's revolution, in his novel several motifs can be identified, which are rooted in the Symbolist tradition. Complex motifs favoured by the Symbolists (the circle, Dante, the path of initiation, knightly ethics, the Rosicrucians) embedded in the world created by the text of The First Circle play a role in generating binary oppositions, they come to transmit semantics of moral and the philosophy of culture.
\end{abstract}

Keywords: The First Circle, Dantean code, initiation novel, Rosicrucians, Grail cup, overriding Social Realism

Почти в каждом, посвященном роману $B$ круге первом анализе отмечается сложность художественной стратегии, которой руководствовался его автор. Один из первых критиков романа, выдающийся писатель Г. Белль пишет следующее: «...книга берет начало от великой русской традиции, она прошла сквозь соцреализм, преодолела и обновила его» (БЕЛЛЬ 1989: 231). Это преодоление соцреалистических стереотипов и клише совершается посредством контаминации реалистических принципов с романтическими, символистскими традициями и прежде всего с традициями высокой духовной и религиозной эстетики Серебряного века ${ }^{2}$. Некоторые аспекты этой традиции трансформируются в реалистической манере романа и вместе с тем обеспечивают метафорическое осмысление этических и философских проблем экзистенциального выбора между добром и злом. Цель

\footnotetext{
${ }^{1}$ ORCID ID: https://orcid.org/0000-0001-7093-778

2 См. «Но, в отличие от классических реалистических романов с их культом „жизнеподобия”, в „Круге первом” устойчивым принципом поэтики становится сцепление натуралистической точности с условностью, придающей образу обобщенно-символическое значение» (ЛЕЙДЕРМАН, ЛИПОВЕЦКИЙ 2003: 275).
} 
настоящей статьи - выявить те мотивы и образы, которые раннее были применены символистами, и вместе с тем показать их интерпретации и трансформации в художественном мире Солженицына.

К символистским обертонам можно причислить, на мой взгляд, и само название романа. Символ круга у Солженицына насыщен множеством значений. Из них стоит выделить и кольцевую композицию: роман начинается с прибытия новых заключенных в спецтюрьму, заканчивается отправкой этапа в лагеря. Рубин, филолог-германист, объясняя новичкам, куда они попали, сравнивает шарашку с первым кругом Дантова ада. «Нет, уважаемый, вы по-прежнему в аду, но поднялись в его лучший высший круг - в первый. Вы спрашиваете, что такое шарашка? Шарашку придумал, если хотите, Данте. Он разрывался - куда ему поместить античных мудрецов? Долг христианина повелевал кинуть этих язычников в ад. Но совесть возрожденца не могла примириться, чтобы светлоумных мужей смешать с прочими грешниками и обречь телесным пыткам. И Данте придумал для них в аду особое место» (СОЛЖЕНИЦЫН 2006: 16). Сходное определение шарашки было дано Нержиным в конце романа: «Нет, Илья Терентьич, это не ад. Это - не ад! В ад мы едем. В ад мы возвращаемся. А шарашка - высший, лучший, первый круг ада. Это почти рай» (СОЛЖЕНИЦЫН 2006: 609).

Несмотря на то, что Данте пришел в русскую культуру сравнительно поздно, во второй половине 18 века, русские символисты «с их мечтой о русском Ренессансе и страстью к аналогиям особенно горячо обращались» (СИЛАРД 2002: 163) к его творчеству. Влиятельный философский журнал Tpydbl $u$ дни наряду с разделами Goetheana, Wagneriana ввел раздел Danteana, подчеркнув этим универсальное значение названных мыслителей. Образы Гете, Вагнера и Данте переплетаются и в художественной ткани солженицынского романа, позитивно оценивающего предреволюционную эпоху, культуру Серебряного века. ${ }^{3}$ Достаточно вспомнить ту сцену, когда один из главных героев, Иннокентий Володин после смерти своей матери разбирает ее шкафы, книги, читает ее письма, дневники и Этические записи: «И фотоальбомы были тут, с четкой ясностью старинных фотографий. И несколько отдельных пачек составляли театральные программки Петербурга и Москвы. И ежедневная театральная газета

\footnotetext{
${ }^{3}$ Вспомним, что по мнению писателя: «Сотрясательная революция, прежде чем взорваться на улицах Петрограда, взорвалась в литературно-художественных журналах петроградской богемы». Ричард Темпест, цитирующий в своей статье это предложение, обращает внимание и на то, что «Солженицын обвиняет модернизм в том, что тот телеологически способствовал национальному краху 1917-го, а не в том, что явился его причиной. Имеется в виду, скорее, вина, может быть, моральное преступление, но не само преступное деяние» (ТЕМПЕСТ 2010).
} 
„Зритель”. И „Вестник кинематографии” - как? это уже все было в то время? И стопы, стопы разнообразных журналов, от одних названий пестрило в глазах: „Аполлон”, „Золотое Руно”, „Гиперборей”, „Пегас”, „Мир искусства”. Репродукции неведомых картин, скульптур (и духа их не было в Третьяковке!), театральных декораций. Стихи неведомых поэтов. Бесчисленные книжечки журнальных приложений - с десятками имен европейских писателей, никогда не слыханных Иннокентием. Да что писателей! - здесь были целые издательства, никому не известные, как провалившиеся в тартарары: „Гриф”, „Шиповник”, „Скорпион”, „Мусагет”, „Альциона”, „Сирин”, „Сполохи”, „Логос”» (СОЛЖЕНИЦЫН 2006: 363).

Семейное культурное и духовное наследие, разговор с живущим уединенно в Твери дядей, а также поездка в убогую, заброшенную деревню Рождество заставляют Иннокентия задуматься над тем, что происходит в стране, и убеждают его в неправильности окружающего мира. Иннокентий постепенно превращается в сомневающегося, борющегося с самим собой героя, который в конце концов решится разомкнуть замкнутый круг, отделяющий друг от друга отечество и человечество. По его представлению существует два круга: большой круг представляет собой человечество, внутри которого расположен меньший - это отечество. Предрассудки и колючие проволоки препятствуют тому, чтобы отечество стало частью этого большого единства. Советский дипломат, государственный советник второго ранга поступает в соответствии с мыслью своего дяди - «Почему любовь к родине надо распространять и на всякое ее правительство? Пособлять ему и дальше губить народ?» (СОЛЖЕНИЦЫН 2006: 371): он своим телефонным звонком в американское посольство и во имя человечества изменяет советскому правительству и передает случайно узнанную информацию о том, где и когда получат советские агенты описание секретной технологии изготовления ядерной бомбы. «Кажется, он успокаивался. Опасно не опасно - другого решения быть не может. Чего-то всегда постоянно боясь - остаемся ли мы людьми?» (СОЛЖЕНИЦЫН 2006: 9)

Хотя Иннокентия поглощает советская тюрьма ${ }^{4}$, его этический выбор, отчаянная попытка изменить ход истории и самопожертвование ради спасения человечества ведут к моральному возвышению и обретению

\footnotetext{
4 Дезинфецирующая одежду машина на Лубянке напоминает Иннокентию жгущее пламя ада. Позднее он спустится глубже первого круга, но до этого он и во внешнем мире проделывает круги: накануне рокового поступка на такси колесит круги по площади перед Лубянкой, почти то же самое происходит и с везущем его в тюрьму фургоном. Круг в произведении является многозначным символом, наряду с метафорой огненного колеса все элементы круга превращаются в ставший историческим символ красного колеса (HETÉNYI 2002: $82)$.
} 
внутренней гармонии. Снисхождение в тюремный ад, в страдание и вместе с тем внутреннее очищение - как путь своеобразного посвящения - роднят его с героем другой сюжетной линии романа, Глебом Нержиным, образ которого полон автобиографических черт. Нержин с фронта сразу попал в исправительный лагерь, потом его перевели в шарашку. Здесь он работает математиком и как бы в качестве реального хранителя памяти пишет книгу о русской революции. Его место испытания, Мавринская шарашка расположена на территории бывшей духовной семинарии, в подгородном одиноком старинном здании, снаружи и внутри наполненном тайнами. Пребывание в шарашке имеет два возможных исхода для арестантов: попасть либо на свободу, к материальным благам, в фальшивый рай советской действительности, либо в лагерь, в нижние ледяные круги ада Гулага. Все зависит от готовности служить делу партии, то есть согласия участвовать в разработке различных аппаратов подслушивания, подсматривания, оказывать техническое содействие советскому режиму. Положение ученых узников пронизано противоречиями, двойственностями, ведь они - представители науки, которыми руководит желание к познанию, приобретению знаний, но достичь этого они могут только ценой компромисса и оппортунизма. Сотрудничество с властью, согласие с тем, что происходит в стране, в конечном итоге воспринимается как сделка с дьяволом. Сологдин, один из ученых-зеков считает, что советская власть - это власть от дьявола. По мнению Рубина любая научная деятельность в шарашке становится сделкой с дьяволом. Неслучайно появляется образ гетевского Фауста, имя которого упоминается Рубиным в его первой беседе с Нержиным.

Уже символисты считали Данте не только и не столько великим поэтом, сколько учителем веры. Эллис, например, связывал путь героя Божественной комедии, «путешественника по загробью» с рыцарским путем истинного познания Истины, посвящением в тайну бытия. В статье о Парсифале Р. Вагнера Эллис называет Данте «единственным, первым и последним поющим великим рыцарем Креста и Вечной Розы» (цит. по СИЛАРД 2002: 169). Мысль о пути рыцарей Розы и Креста затронула не только последователей Р. Штейнера, Эллиса и А. Белого, она коснулась и Вяч. Иванова, Н. Бердяева и А. Блока. В символистских размышлениях о посвятительном пути придавалось особое значение розенкрейцерству. Символисты усердно изучали Романы круглого стола, такие мотивы Артурова цикла, как поиски Святого Грааля, были необыкновенно значимы в культуре Серебряного века .

В Круге первом центральный символ - рыцари Грааля. Центральная, сорок шестая глава носит название Замок святого Грааля. По мнению исследователя Жоржа Нива, это таинственный центр произведения, его средоточие, «ось книги» (НИВА 2003). Символические смыслы Грааля обычно сводятся к поиску нравственного совершенства, божественного 
откровения, к идее триединства истины, добра и красоты, к теме избранничества, рыцарского служения. Можно сказать, что все перечисленные смыслы данного символа проявляются и в романе Солженицына, видящего в Граале - согласно христианской традиции духовную первооснову, сущность мира. В шарашке работает художникзек Кондрашев-Иванов ${ }^{5}$ «в качестве крепостного живописца»: от него требуют украсить вестибюли и залы отдела спецтехники и квартиры замминистра и близких к нему работников большими портретами и патриотическими картинами. Он, в одиночестве, работает над своими полотнами, ведет поиск равновесия между силой и светом, Невидимого и Совершенного, синтеза «понимания, успокоения, все-соединения». Его главная картина, детальное описание которой дается в романе ${ }^{6}$, разрабатывает вагнеровскую тему. Это тема духовного путешествия, поиска Святого Грааля, достижения места, откуда виден иной мир, образ Совершенства. Парсифаль впервые видит замок святого Грааля. Следует упомянуть, что Парсифаль стал рыцарем Грааля после того, как победил искушение и вернул святое копье королю Грааля, Амфортасу. Рыцарь поднимается по крутой тропе над бездной, по «клиновидной щели между двумя сдвинутыми горными обрывами» с крайними деревьями «леса дремучего, первозданного» (СОЛЖЕНИЦЫН 2006: 278). Верхняя часть полотна залита оранжевым светом, «исходящим то ли от Солнца, то ли от чего-то еще чище Солнца, скрытого от нас за замком. Вырастая из уступчатой горы, сам в уступах и башенках, видимый и внизу сквозь клиновидную щель, и в разломе между скалами, папоротниками, деревьями, игловидно поднимаясь на всю высоту картины до небесного зенита, - не чётко-реальный, но как бы сотканный из облаков, чуть колышистый, смутный и всё же угадываемый в подробностях нездешнего совершенства, - стоял в ореоле невидимого сверх-Солнца сизый замок святого Грааля» (СОЛЖЕНИЦЫН 2006: 278). Достигнув перевала,

\footnotetext{
5 Прообразом героя романа И. М. Кондрашева-Иванова является живописец и график С. М. Ивашев-Мусатов, старший товарищ Солженицына по Марфинской шарашке. Его живописные и графические произведения декоративным характером и колористической насыщенностью напоминают картины бубнововалетовцев, однако мистический подтекст сближает его картины с опытом символизма. О творчестве художника и роли экфрастических описаний его картины в романном повествовании подробнее см. ДРОНОВА 2014.

${ }^{6}$ См. «В окончательную редакцию романа включены экфрасисы пяти работ художника, некоторые с измененными писателем названиями: „Первый снег”, „Дуб” („Изувеченный дуб”), „Натюрморт с медным кувшином” („Натюрморт с подносом”), „Девушка в противоипритном костюме. Москва. 1941 год”, „Замок святого Грааля”. Упоминается также пейзаж „Утро” („Утро необыкновенного дня"). В раннем варианте (в 3-й редакции 1959 г., перепечатка 1961-1962 гг.) была еще одна работа - „Натюрморт с гипсовой головой” („Натюрморт со статуэткой и книгой”)» (ДРОНОВА 2014: 58).
} 
рыцарь открывает сияние Вечности. По мнению создателя картины, этот момент может быть у каждого человека, достижение морального совершенства возможно для всех: «... каждый человек носит в себе Образ Совершенства, который иногда затемнен, а иногда так явно выступает! И напоминает ему его рыцарский долг!» (СОЛЖЕНИЦЫН 2006: 277) В споре-разговоре с Нержиным художник выступает за рыцарей: «А кого не хватает нашему веку? Членов партий? Нет, уважаемый - не хватает рыцарей! При рыцарях не было концлагерей! И душегубов не было» (СОЛЖЕНИЦЫН 2006: 277).

На символическом распутье находятся «рыцари» произведения Солженицына, они должны в одиночку выбирать свою дорогу. Вопрос о посвящении как избранничестве, избранности на этической основе отчетливо формулируют и узники. Математики иронично называются инженером-полковником госбезопасности розенкрейцерами, к таинствам которых Яконову не пришлось приобщиться. Розенкрейцеры, то есть люди, соединенные в тайное братство, в котором культивировалось знание, недоступное посторонним: знание подлинного строения человека и его связи с космосом. Они стремились соединить учение о внешней природе со знанием о природе внутренней, природе души. В розенкрейцерстве большой вес приобретает индивидуально осваиваемая наука. Закрытая структура и культ знания роднит спецтюрьму МГБ 1 с оккультным орденом, но узники - именно как и масоны ${ }^{7}-$ больше сосредоточиваются на этических, общественных вопросах, касающихся политической, преобразующей деятельности. В интеллектуальном поле романа большое место отводится идеологическим спорам, диалогам, диспутам, полемикам, разговорам, размышлениям, интеллектуальным играм узников шарашки, носителей культуры. Мудрецы вступают в дискуссию друг с другом, в том числе устраивают суд над князем Игорем, спорят о советском строе, о разумно устроенном обществе и разговаривают о том, почему Моисей сорок лет водил евреев по Аравийской пустыне. Как на это указывают исследователи, интеллектуальное ядро романа образует спор трех центральных персонажей, Нержина, Сологдина и Рубина (ЛЕЙДЕРМАН, ЛИПОВЕЦКИЙ 2003: 281). Они - Рыцари идеи, их стремление к тайному, запретному знанию, исследовательский пыл являются их неизменными чертами. Рубин - библейский фанатик по Сологдину - и после ареста и опыта долгой жизни в лагере не потерял веру в Сталина, оставаясь преданным советской власти. Его противник, Сологдин, пережив сложный внутренний спор в поиске совершенства, также идет на компромисс. В ситуации выбора из них только Глеб Нержин отказывается от сотрудничества с угнетателями во имя сохранения нравственного

\footnotetext{
7 Разграничение розенкрейцерства и масонства в России отдельный вопрос, освещение которого выходит за рамки данной работы.
} 
достоинства человека и спасения бессмертной души. Его стратегия поведения, аскетизм воспринимается как единственный способ сохранения внутренней свободы и обретения согласия с самим собой.

Символами утраты нравственных устоев в советском обществе и удаления самого понятия о вечности из духовной сферы являются развалины церкви Никиты Мученика и образ разоренной церкви в деревне Рождество. Руины и странное для советской топонимики и несмотря на это не измененное название деревни напоминают о времени, когда все было на своих местах: и Бог, и рай, и ад. И хотя настоящее положение является перевернутым и в стране господствуют силы зла, финал романа свидетельствует о возможности сохранить ценности, противостоять разрушению и при этом обрести мир.

«Прислушиваясь к ходу машины, зэки смолкли.

Да, их ожидала тайга и тундра, полюс холода Оймякон и медные копи Джезказгана. Их ожидала опять кирка и тачка, голодная пайка сырого хлеба, больница, смерть. Их ожидало только худшее.

Но в душах их был мир с самими собой.

Ими владело бесстрашие людей, утерявших все до конца, бесстрашие, достающееся трудно, но прочно» (СОЛЖЕНИЦЫН 2006: 609).

В соответствии с пронизывающей романную ткань христианской символикой, путь к бесстрашию, к размыканию узкого круга отечества, становлению свободной личности ведет только через жертву, через смерть - возрождение в духе Христа. В отличие от романов инициации символистов, в произведении Солженицына выделяется и подчеркивается этический аспект. Другая реальность - это не абстрактный мир, выстроенный из мифопоэтических элементов, а истина лагерных заключенных и угнетенных, которые противостоят лжи сталинистской эпохи. Излюбленные мотивы символистов, наполненные сложными смыслами (путь посвящения, круг, розы и крест, замок Грааля, тамплиеры, рыцари) в романе Солженицына направлены на создание бинарных оппозиций, становясь носителями моральных, политических, культурно-исторических смыслов в земном конкретном историческом и автобиографическом пространстве.

\section{Литература}

БЁЛЛЬ 1989 = БЁЛЛЬ Г. Мир под арестом // Иностранная литература, 1989. № 8. 228-233.

ДРОНОВА $2014=$ ДРОНОВА Т.И. Экфрасис как прием в романе А.И. Солженицына «В круге первом» // Известия Саратовского университета. Новая серия. Сер. Филология. Журналистика. 2014. Т. 14, вып. 2. 57-64.

ЛЕЙДЕРМАН, ЛИПОВЕЦКИЙ 2003 = ЛЕЙДЕРМАН Н.Л., ЛИПОВЕЦКИЙ М.Н.

Современная русская литература: 1950-1990-е годы. В 2 т. Т. 2. Москва, 2003. 
НИВА 2003 = НИВА Ж. Поэтика Солженицына между «большими» и «малыми» формами // Звезда, 2003. №12. 143-147. http://magazines.russ.ru/zvezda/ 2003/12/niva.html

СИЛАРД 2002 = СИЛАРД Л. Дантов код русского символизма // Силард Л. Герметизм и герменевтика. СПб., 2002.162-205.

СОЛЖЕНИЦЫН 2006 = СОЛЖЕНИЦЫН А. В круге первом. Москва, 2006.

ТЕМПЕСТ 2010 = ТЕМПЕСТ Р. Александр Солженицын - (анти)модернист // Новое литературное обозрение, 2010. №3. 246-263. http://magazines. russ.ru/nlo/2010/103/te17.html

HETÉNYI 2002 = HETÉNYI ZS. Szolzsenyicin // Az orosz irodalom története 1941től napjainkig. Szerk. Hetényi Zs. Budapest, 2002. 66-91. 